\title{
Association of angiotensin II type 1 receptor gene A1166C polymorphism with steroid sensitivity in children with nephrotic syndrome
}

\author{
Parvaneh Rahimi-Moghaddam ${ }^{\circledR}$, Seyyed Amir Yasin Ahmadi $^{2}$, Rozita Hoseini ${ }^{3}$, Mehdi Chinichian ${ }^{4}$, Parisadat \\ Ahmadi $^{5^{*}(\mathbb{D})}$ \\ ${ }^{1}$ Department of Pharmacology, Iran University of Medical Sciences, Tehran, Iran \\ ${ }^{2}$ Exceptional Talent Development Center, Education Development Center, Lorestan University of Medical Sciences, Khorramabad, Iran \\ ${ }^{3}$ Pediatric Renal Transplantation and Dialysis Research Center, Iran University of Medical Sciences, Tehran, Iran \\ ${ }^{4}$ Iran University of Medical Sciences, Tehran, Iran \\ ${ }^{5}$ Pediatric Growth and Development Research Center, Institute of Endocrinology and Metabolism, Iran University of Medical Sciences, Tehran, Iran
}

\section{A R T I C L E I N F O}

Article Type:

Original

\section{Article History:}

Received: 4 October 2018

Accepted: 10 December 2018

ePublished: 4 January 2019

\section{Keywords:}

Nephrotic syndrome

Angiotensin receptor

Polymorphism

Pharmacogenomics

\begin{abstract}
A B S T R A C T
Introduction: In children, nephrotic syndrome is usually idiopathic. Cases are considered as minimal change disease until proven otherwise. The children who respond to steroid are called steroid sensitive, and the children who do not respond to steroid are called steroid resistant.

Objectives: According to the role of genetic in effectiveness of steroid therapy of children with idiopathic nephrotic syndrome, we designed this study to investigate the role of angiotensin II type 1 receptor $(A T 1 R)$ gene $\mathrm{A} 1166 \mathrm{C}$ polymorphism in such conditions.

Patients and Methods: This single center study was conducted on Iranian children in Hazarat Ali Asghar hospital, Tehran, Iran. A total of 40 patients (including 18 steroid resistant and 22 steroid sensitive patients) were selected. Total DNA samples were taken from peripheral blood. Polymerase chain reaction (PCR) was used for genotyping.

Results: In this study, the association of AT1R gene A1166C polymorphism with groups including steroid sensitive and steroid resistant groups was not significant $(P>0.05)$. We also found a significant difference of systolic blood pressure between steroid sensitive and steroid resistant group with more values in steroid resistant group $(P=0.0327)$.

Conclusion: This low power single center study could not show any significant association for this polymorphism in Iranian population. Resistance to steroid therapy was associated with higher systolic blood pressure.
\end{abstract}

Implication for health policy/practice/research/medical education:

This single center study could not show any significant association of angiotensin II type 1 receptor gene A1166C polymorphism with steroid sensitivity in children with nephrotic syndrome in Iranian population. Resistance to steroid therapy in children with nephrotic syndrome was associated with higher systolic blood pressure.

Please cite this paper as: Rahimi-Moghaddam P, Ahmadi SAY, Hoseini R, Chinichian M, Ahmadi P. J Nephropharmacol. 2019;8(1):e11. DOI: 10.15171/npj.2019.11.

\section{Introduction}

Nephrotic syndrome is a series of symptoms and signs resulted from the proteinuria and the hyperlipidemia due to glomerulopathy. According to the type of glomerulopathy based on its histopathology, nephrotic syndrome mainly falls into the following categories; minimal change disease, focal and segmental glomerulosclerosis (FSGS), membranous nephropathy, and the cases resulted from diabetic nephropathy, systemic lupus erythematous or amyloidosis $(1,2)$.
In children, nephrotic syndrome is usually idiopathic. Since taking biopsy is an invasive procedure, all of pediatric cases are considered minimal change disease until proven otherwise. After clinical diagnosis of nephrotic syndrome, steroid therapy is started. The children who respond to steroid are called steroid sensitive. The children who do not respond to steroids are called steroid resistant. In steroid sensitive patients, biopsy will not be indicated and the diagnosis must be minimal change disease. In steroid resistant patients, biopsy may be indicated and diagnosis 
is usually FSGS (3). About $10 \%$ of children with nephrotic syndrome are steroid resistant. Approximately half of them are at risk of end-stage renal disease (4).

Renin-angiotensin is an endocrine system controlling blood pressure, blood volume and blood electrolytes. Angiotensin converting enzyme (ACE) and angiotensin II type 1 receptor (AT1R) are important involving elements of this system. Dysfunction of this system is associated with a variety of disorders such as hypertension, nephrotic syndrome (2,5), preeclampsia (6), polycystic ovary syndrome (7) and kidney allograft dysfunction $(8,9)$.

Several studies have shown that $A T 1 R$ gene is polymorphic. It has been shown that some genotypes of such genes are associated with different types of diseases. From the viewpoint of population genetics, distribution of alleles and genotypes are different among ethnicities (10). Response to steroid therapy is considered as a genetic associated condition (3).

\section{Objectives}

According to the genetic role in effectiveness of steroid therapy of children with idiopathic nephrotic syndrome, we designed this study to investigate the role of $A T 1 R$ gene $A 1166 C$ polymorphism in such conditions on Iranian children. As well, the role of blood pressure and laboratory profile were investigated.

\section{Patients and Methods}

\section{Study population}

This observational study was conducted as a single center genetic association study on Iranian children in Hazarat Ali Asghar hospital, Iran University of Medical Sciences, Tehran, Iran. A total of 40 children (including 18 steroid resistant and 22 steroid sensitive) with idiopathic nephrotic syndrome were selected through convenient sampling. The patients had been diagnosed through clinical practice and confirmed by proteinuria more than $40 \mathrm{mg} / \mathrm{m}^{2} / \mathrm{h}$ (11). Sensitivity or resistance to steroid therapy had been investigated based on follow up.

\section{Laboratory assay}

After taking informed consent from the parents, $2 \mathrm{~mL}$ of peripheral blood was taken from each child. Total DNA was extracted through salting out method. Polymerase chain reaction (PCR) was used for genotyping AT1R gene A1166C polymorphism.

\section{Ethical issues}

Tenets of the Helsinki Declaration was regarded. Written informed consent was taken from the parents. The ethics committee of Iran University of Medical Sciences (thesis\# 20673; M.D thesis of Parisadat Ahmadi) approved the study.

\section{Statistical analysis}

Genotypes were compared among the groups by Fisher's exact test. Kolmogorov-Smirnov test was used to evaluate normal distribution of numerical data. Numerical data among the groups were analyzed by independent $t$ test or Wilcoxon rank (Mann Whitney U) test. Two-tailed $P$ value was reported using STATA 14 (StataCorp LLC, US) at alpha error level of 0.05 .

\section{Results}

For each participant, gender, age of disease onset, age of refer at the time of research, familial history, systolic blood pressure, diastolic blood pressure, hemoglobin, serum creatinine, serum albumin and total cholesterol were reported. Moreover, three genotypes of $A A, A C$ and $C C$ were reported. The individual participant data are shown in Table 1.

In this study, the association of ATIR gene A1166C polymorphism with study groups including steroid sensitive and steroid resistant groups was not significant. For numerical data, Kolmogorov-Smirnov test showed a normality rejection for systolic blood pressure of the groups. We found a significant difference of systolic blood pressure between the steroid sensitive and the steroid resistant groups with more values in the steroid resistant group ( $\mathrm{P}=0.0327$; Wilcoxon rank test) (Figure 1$)$. No significant result was observed for other numerical data.

\section{Discussion}

This study had been hypothesized based on the association of AT1R gene A1166C polymorphism and sensitivity or resistance to steroid therapy in children with idiopathic nephrotic syndrome. In contrast to our hypothesis, no significant result was observed for this association. Among demographic, clinical and para- clinical characteristics of the participants, only the association of systolic blood pressure was statistically significant in favor of steroid resistance.

In 1990, it was reported that hypertension is a common feature of nephrotic syndrome, while it was not related to steroid therapy and renal failure (12). There are few studies on the association of hypertension and steroid resistance. Therefore, the finding of our study can be used as a piece of evidence. Among the genetic association studies, most of them were related to ACE gene polymorphism.

\section{Conclusion}

This low power single center study could not show any significant association for this polymorphism on Iranian population. In other hands, resistance to steroid therapy was associated with higher systolic blood pressure. Thus, this evaluation should be performed in other populations with larger sample size.

\section{Limitations}

The low power of this study was the main limitation to reach a potential significant result of this genetic association study. Among the other limitations it can be 
Table 1. Individual participant data of the study

\begin{tabular}{|c|c|c|c|c|c|c|c|c|c|c|c|}
\hline ID\# & $\begin{array}{l}\text { Disease } \\
\text { onset (y) }\end{array}$ & Gender & $\begin{array}{l}\text { Familial } \\
\text { history }\end{array}$ & $\begin{array}{c}\text { Follow up } \\
\text { age (y) }\end{array}$ & $\begin{array}{l}\text { Creatinine } \\
\text { (mg/dL) }\end{array}$ & $\begin{array}{c}\text { Systolic BP } \\
\text { (mm Hg) }\end{array}$ & $\begin{array}{c}\text { Diastolic BP } \\
\text { (mm Hg) }\end{array}$ & $\begin{array}{l}\text { Hemoglobin } \\
(\mathrm{g} / \mathrm{dL})\end{array}$ & $\begin{array}{l}\text { Albumin } \\
\text { (g/dL) }\end{array}$ & $\begin{array}{l}\text { Cholesterol } \\
\text { (mg/dL) }\end{array}$ & $\begin{array}{l}\text { Genotype } \\
\text { (A1166C) }\end{array}$ \\
\hline SR-1 & 1.33 & $M$ & - & 5.00 & 0.72 & 95.00 & 78.00 & 13.40 & 2.60 & 305.00 & $A A$ \\
\hline SR-2 & 2.50 & $\mathrm{~F}$ & - & 7.58 & 0.61 & 111.00 & 69.00 & 14.10 & 1.50 & 245.00 & $A C$ \\
\hline SR-3 & 1.25 & M & - & 3.08 & 0.64 & 115.00 & 81.00 & 14.20 & 2.50 & 195.00 & $A C$ \\
\hline SR-4 & 2.00 & $\mathrm{~F}$ & - & 5.33 & 0.58 & 114.00 & 60.00 & 13.90 & 2.40 & 420.00 & $\mathrm{CC}$ \\
\hline SR-5 & 3.41 & $\mathrm{~F}$ & + & 6.00 & 0.46 & 120.00 & 70.00 & 14.00 & 1.40 & 210.00 & $A A$ \\
\hline SR-6 & 2.50 & M & - & 4.67 & 0.33 & 102.00 & 74.00 & 13.80 & 2.50 & 351.00 & AA \\
\hline SR-7 & 3.91 & $M$ & - & 7.08 & 0.51 & 116.00 & 59.00 & 12.30 & 3.60 & 368.00 & $A C$ \\
\hline SR-8 & 1.25 & M & - & 3.00 & 0.76 & 100.00 & 65.00 & 13.50 & 2.40 & 186.00 & $A C$ \\
\hline SR-9 & 4.08 & $\mathrm{~F}$ & - & 4.91 & 0.62 & 114.00 & 61.00 & 14.10 & 1.60 & 190.00 & AA \\
\hline SR-10 & 3.00 & $\mathrm{~F}$ & - & 6.50 & 0.59 & 99.00 & 75.00 & 13.90 & 3.50 & 310.00 & CC \\
\hline SR-11 & 2.67 & $M$ & - & 6.50 & 0.65 & 94.00 & 79.00 & 13.80 & 1.80 & 314.00 & AA \\
\hline SR-12 & 1.91 & $M$ & - & 4.17 & 0.76 & 113.00 & 79.00 & 12.90 & 2.10 & 324.00 & $A A$ \\
\hline SR-13 & 2.75 & $\mathrm{~F}$ & - & 8.17 & 0.37 & 109.00 & 60.00 & 13.80 & 1.50 & 311.00 & $A C$ \\
\hline SR-14 & 1.58 & M & - & 6.41 & 0.47 & 115.00 & 78.00 & 13.50 & 2.60 & 319.00 & $A C$ \\
\hline SR-15 & 2.75 & $\mathrm{~F}$ & + & 3.83 & 0.23 & 120.00 & 77.00 & 14.20 & 1.70 & 125.00 & AA \\
\hline SR-16 & 3.08 & $M$ & - & 3.33 & 0.66 & 119.00 & 63.00 & 13.70 & 1.60 & 351.00 & $A A$ \\
\hline SR-17 & 1.25 & $\mathrm{~F}$ & - & 2.83 & 0.79 & 132.00 & 80.00 & 14.20 & 1.30 & 314.00 & $A C$ \\
\hline SR-18 & 3.67 & $M$ & - & 7.25 & 0.58 & 110.00 & 61.00 & 14.10 & 1.90 & 360.00 & $A A$ \\
\hline SS-1 & 3.25 & $\mathrm{~F}$ & - & 7.58 & 0.68 & 111.00 & 91.00 & 15.80 & 2.40 & 375.00 & AA \\
\hline SS-2 & 2.08 & $M$ & - & 5.41 & 0.30 & 82.00 & 62.00 & 13.80 & 1.30 & 214.00 & $A A$ \\
\hline SS-3 & 1.91 & $\mathrm{~F}$ & - & 5.50 & 0.45 & 84.00 & 76.00 & 15.10 & 1.90 & 290.00 & $A C$ \\
\hline SS-4 & 4.25 & $\mathrm{~F}$ & - & 6.41 & 0.49 & 93.00 & 82.00 & 11.40 & 2.10 & 235.00 & $A A$ \\
\hline SS-5 & 2.50 & $M$ & - & 5.50 & 0.56 & 110.00 & 89.00 & 10.50 & 2.50 & 249.00 & $A A$ \\
\hline SS-6 & 1.91 & $M$ & - & 5.83 & 0.71 & 95.00 & 85.00 & 11.80 & 2.50 & 287.00 & AA \\
\hline SS-7 & 3.58 & $\mathrm{~F}$ & - & 4.67 & 0.42 & 84.00 & 83.00 & 12.50 & 1.80 & 352.00 & $A C$ \\
\hline SS-8 & 2.17 & $\mathrm{~F}$ & - & 3.67 & 0.39 & 116.00 & 76.00 & 13.90 & 1.40 & 345.00 & $A C$ \\
\hline SS-9 & 3.25 & $\mathrm{~F}$ & - & 7.08 & 0.65 & 121.00 & 83.00 & 14.30 & 1.60 & 321.00 & $A A$ \\
\hline SS-10 & 4.08 & $\mathrm{~F}$ & - & 4.50 & 0.48 & 89.00 & 65.00 & 13.20 & 2.10 & 256.00 & AA \\
\hline SS-11 & 1.83 & $\mathrm{~F}$ & - & 5.17 & 0.35 & 95.00 & 74.00 & 9.50 & 2.50 & 230.00 & $A A$ \\
\hline SS-12 & 2.33 & $M$ & - & 5.33 & 0.67 & 115.00 & 69.00 & 12.80 & 2.40 & 301.00 & $A C$ \\
\hline SS-13 & 2.33 & $M$ & - & 6.17 & 0.49 & 92.00 & 79.00 & 13.40 & 1.50 & 295.00 & $A C$ \\
\hline SS-14 & 3.75 & $\mathrm{~F}$ & - & 4.91 & 0.47 & 84.00 & 90.00 & 14.60 & 1.80 & 256.00 & $\mathrm{CC}$ \\
\hline SS-15 & 3.67 & $M$ & - & 3.50 & 0.57 & 73.00 & 56.00 & 13.90 & 2.60 & 261.00 & $A C$ \\
\hline SS-16 & 2.67 & $\mathrm{~F}$ & - & 7.41 & 0.36 & 119.00 & 57.00 & 14.80 & 2.10 & 201.00 & $A A$ \\
\hline SS-17 & 4.41 & $M$ & - & 6.91 & 0.54 & 106.00 & 91.00 & 15.80 & 2.20 & 304.00 & $A C$ \\
\hline SS-18 & 5.08 & $M$ & - & 7.75 & 0.28 & 96.00 & 89.00 & 14.60 & 1.70 & 295.00 & $A A$ \\
\hline SS-19 & 2.33 & $M$ & - & 7.75 & 0.75 & 129.00 & 77.00 & 10.20 & 1.60 & 305.00 & $A A$ \\
\hline SS-20 & 4.33 & $\mathrm{~F}$ & - & 5.83 & 0.62 & 102.00 & 65.00 & 12.90 & 1.70 & 264.00 & $A A$ \\
\hline SS-21 & 1.91 & $\mathrm{~F}$ & - & 6.67 & 0.90 & 121.00 & 80.00 & 13.80 & 1.10 & 310.00 & AA \\
\hline SS-22 & 1.83 & $M$ & - & 6.50 & 0.41 & 81.00 & 63.00 & 15.10 & 1.70 & 245.00 & $A C$ \\
\hline
\end{tabular}

SR: steroid resistant; SS: steroid sensitive; BP: blood pressure; M: male; F: female.

Each month was considered equal to 0.08 of a year. 


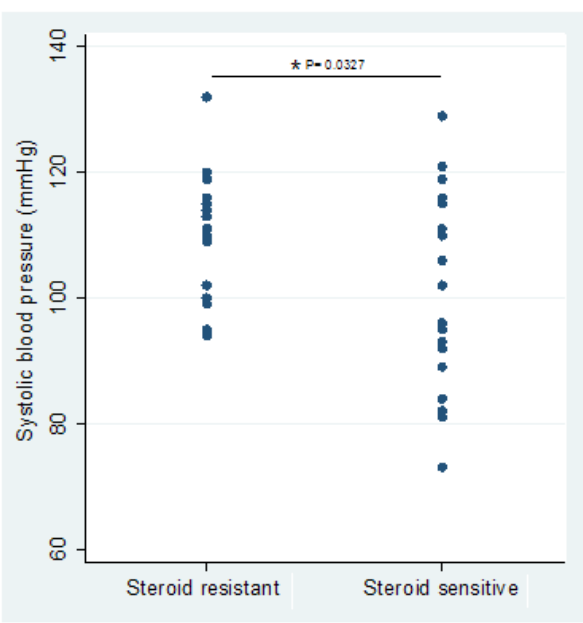

Figure 1. Distribution and rank of systolic blood pressure of each participants in the two groups. Wilcoxon rank test shows a positive significant association $(P=0.0327)$.

pointed out that, the laboratory data had bias because the patients were at different stages of treatment and follow up. This study was not cross-sectional and therefore the prevalence of steroid resistance was not real. Lack of healthy control group was another limitation.

\section{Acknowledgments}

This study was extracted from the M.D thesis of Parisadat Ahmadi approved by Iran University of Medical Sciences.

\section{Authors' contribution}

PA collected samples and performed clinical evaluations. SAYA conducted statistical analysis and wrote the primary draft and final revision. $\mathrm{RH}$ acted as a co-supervision and clinical consultant. MC helped in collecting data. PR managed laboratory assays.. The first and corresponding authors are the main contributors due to taking biological samples and molecular studies.

\section{Conflicts of interest}

There is no conflict of interest.

\section{Ethical considerations}

Ethical issues (including plagiarism, data fabrication, double publication) have been completely observed by the authors.

\section{Funding/Support}

Iran University of Medical Sciences (Grant \#20673) supported this study.

\section{References}

1. Ahmadi P, Hoseini R, Rahimi-Moghaddam P, Ahmadi SAY. Sensitivity or resistance to steroid therapy in children with idiopathic nephrotic syndrome is not associated with polymorphism of angiotensin converting enzyme (ACE). J Appl Pharm Sci. 2016;6:206-8. doi: 10.7324/ JAPS.2016.601231

2. Ahmadi P, Ahmadvand H, Ahmadi SAY, Hoseini R, Rahimi-Moghaddam P. A narrative review on nephrotic syndrome emphasizing its correlation with polymorphism of angiotensin converting enzyme and renin-angiotensin system. Cres J Med Biol Sci. 2017;4:41-6.

3. Noone DG, Iijima K, Parekh R. Idiopathic nephrotic syndrome in children. The Lancet. 2018;392:61-74. doi: 10.1016/S0140-6736(18)30536-1

4. Banerjee A, Divyaveer SS, Malvade P, Das Bhattacharya T, Mahajan C, Tiwari V, et al. A prospective trial of safety and efficacy of low-dose tacrolimus therapy in steroid resistant nephrotic syndrome. J Nephropharmacol. 2018;7:18-23. doi: 10.15171/npj.2018.05

5. Moslemi F, Taheri P, Azimipoor M, Ramtin S, Hashemianfar M, Momeni- Ashjerdi A, et al. Effect of angiotensin II type 1 receptor blockade on kidney ischemia/reperfusion; a gender-related difference. J Renal Inj Prev. 2016;5:140-3. doi: $10.15171 /$ jrip.2016.29

6. Li Y, Zhu $\mathrm{M}, \mathrm{Hu} \mathrm{R}$, Yan $\mathrm{W}$. The effects of gene polymorphisms in angiotensin II receptors on pregnancyinduced hypertension and preeclampsia: a systematic review and meta-analysis. Hyperten Pregnancy. 2015;34:241-60. doi: $\quad 10.3109 / 10641955.2015 .1009543$

7. Yari F, Aeinfar K, Abbaszadeh S, Anbari K, Ahmadi SAY. Polycystic ovary syndrome is affected and protected by DD and DI genotypes of angiotensin converting enzyme, respectively: an update of a meta-analysis. Int J Wom Health Reprod Sci. 2017;5:164-70. doi: 10.15296/ijwhr.2017.30

8. Savaj S, Hosseini SG, Ghods AJ. Effect of Angiotensin II Receptor Type 1 Antibodies on Kidney Allograft Function. Iran J Kidney Dis. 2018;12:120.

9. Azmandian J, Mohamadifar M, Rahmanian-Koshkaki S, Mehdipoor M, Nematollahi M-H, Saburi A, et al. Study of the association between the donors and recipients angiotensin-converting enzyme insertion/deletion gene polymorphism and the acute renal allograft rejection. J Nephropathol. 2015;4:62-8. doi: 10.12860/jnp.2015.13

10. Liu D-X, Zhang Y-Q, Hu B, Zhang J, Zhao Q. Association of AT1R polymorphism with hypertension risk: an update meta-analysis based on 28,952 subjects. J Renin Angiotensin Aldosterone Syst. 2015;16:898-909. doi: 10.1177/1470320315584096

11. Hoseini R, Sabzian K, Otukesh H, Zafaranloo N, Panahi P, Rahimzadeh N, et al. Efficacy and Safety of Rituximab in Children With Steroid- and Cyclosporine-resistant and Steroid- and Cyclosporine-dependent Nephrotic Syndrome. Iran J Kidney Dis. 2018;12:27-32.

12. Küster S, Mehls O, Seidel C, Ritz E. Blood Pressure in Minimal Change and Other Types of Nephrotic Syndrome. Am J Nephrol. 1990;10:76-80. doi: 10.1159/000168198

Copyright $\odot 2019$ The Author(s); Published by Society of Diabetic Nephropathy Prevention. This is an open-access article distributed under the terms of the Creative Commons Attribution License (http://creativecommons.org/licenses/by/4.0), which permits unrestricted use, distribution, and reproduction in any medium, provided the original work is properly cited. 